\section{Sensitivities of mRNA Expression of Vitellogenin, Choriogenin and Estrogen Receptor by Estrogenic Chemicals in Medaka, Oryzias latipes}

\author{
Chulwoo Lee, ${ }^{a}$ Seong Hwan Jeon, ${ }^{a}$ \\ Jin-Gyun Na, ${ }^{a}$ Yong-Jin Choi, ${ }^{b}$ \\ and Kwangsik Park*,a, 1
}

${ }^{a}$ Risk Research Department, National Institute of Environmental Research, Gyeongseo-dong, Seo-gu, Incheon 404-170, Korea and ${ }^{b}$ Laboratory of Microbial Genetics, Graduate School of Biotechnology, Korea University, \#5-1, Anam-dong, Seongbuk-gu, Seoul 136-701, Korea

(Received March 6, 2002; Accepted May 20, 2002)

Gene expression levels of choriogenin, vitellogenin, and estrogen receptor were determined using a reverse transcription-polymerase chain reaction (RT-PCR) technique after exposure to estrogenic chemicals to compare the sensitivities of the biomarkers of endocrine disruption in medaka, Oryzias latipes. Mature male medaka were treated with a single dose of $100 \mu$ / l of $17 \alpha$-ethinylestradiol, nonylphenol, and bisphenol A for 6 days, then RNA was extracted from the livers of treated fish for RT-PCR. Primers of RT-PCR for choriogenin $H$ and $L$, and estrogen receptor were synthesized based on previously known cDNA sequences, and primers for vitellogenin I and II were synthesized based on the partial cDNA which was sequenced in this study. When the five biomarker genes were amplified by RT-PCR under the same condition, the mRNA induction level of each gene was elevated with different sensitivities. Conclusively, choriogenin L, which is a precursor of zona radiata protein (ZI-3) with molecular weight of $49 \mathrm{kD}$, showed the most sensitive gene expression in all the treated groups.

Key words — medaka, vitellogenin, choriogenin, estrogen receptor

\footnotetext{
'Present address: College of Pharmacy, Dongduk Women's University, \#23-1, Wolgok-dong, Seongbuk-gu, Seoul 136-714, Korea.

*To whom correspondence should be addressed: College of Pharmacy, Dongduk Women's University, \#23-1, Wolgok-dong, Seongbuk-gu, Seoul 136-714, Korea. Tel.: +82-2-940-4522; Fax: +82-2-940-4195; E-mail: envipark@hanmail.net
}

\section{INTRODUCTION}

Endocrine disruptors are hormone-mimics that modify hormonal action in humans and animals. ${ }^{1)}$ There is increasing concern about endocrine disruptors, especially environmental estrogens because of their ability to mimic natural hormones and to influence vital reproductive functions in humans and wildlife. Recently, Organization for Economic Cooperation and Development (OECD) has been working to revise the existing test guidelines and/or prepare new guidelines to screen and test endocrine disrupting chemicals. They agreed to define the endpoints of endocrine disruption in fish as gross morphology, gonad histology and biological markers such as vitellogenin in the $2^{\text {nd }}$ OECD Expert Consultation Meeting on Endocrine Disruptors Testing in Fish, held in Tokyo, $15^{\text {th }}-16^{\text {th }}$ March, 2000. ${ }^{2)}$ Regarding the biomarkers of endocrine disruption in fish, recent research has focused on vitellogenin, choriogenin, estrogen receptor, and P450aromatase, ${ }^{3-7)}$ but the screening and testing methods using the biomarkers have not yet been fully validated.

Recently, it was reported that choriogenin was more responsive to environmental estrogens than vitellogenin in Atlantic salmon, as determined by Enzyme-linked Immunosorbent Assay (ELISA). ${ }^{8)}$ However, no study attempted to compare responsiveness to estrogenic chemicals with the gene expression of possible biomarkers.

In the present study, mRNA induction levels of choriogenin $\mathrm{H}$ and L, vitellogenin I and II, and estrogen receptor in the medaka exposed to $17 \alpha$ ethinylestradiol, nonylphenol, and bisphenol A were compared using the reverse transcription-polymerase chain reaction (RT-PCR) method.

\section{MATERIALS AND METHODS}

Fish and Chemical Exposure — The orangered variety of the adult medaka (Oryzias latipes) were maintained at the Environmental Toxicology Laboratory, National Institute of Environmental Research of Korea. They were raised under constant light/dark cycles of $18 / 6 \mathrm{hr}$ and a temperature of $25 \pm 1{ }^{\circ} \mathrm{C}$. They were fed ad libitum three times, once with artemia and twice with commercial flake food. For the induction of mRNA expression of vitellogenin, choriogenin, and estrogen receptor, male medaka with a mean weight of $250 \mathrm{mg} /$ fish 
Table 1. Primer Sequences for RT-PCR of Choriogenin, Vitellogenin and Estrogen Receptor

\begin{tabular}{|c|c|}
\hline Gene name & Primer sequences \\
\hline \multirow[t]{2}{*}{ Choriogenin L } & $\mathrm{F}: 5^{\prime}$ - GCCAAACCTGTAGTGCCATT $-3^{\prime}$ \\
\hline & $\mathrm{R}: 5^{\prime}$ - CTGCTCCACTGACCTCCTTC $-3^{\prime}$ \\
\hline \multirow[t]{2}{*}{ Choriogenin $\mathrm{H}$} & F : $5^{\prime}$ - CGCCATCTACTACTTTCCCG -3' \\
\hline & $\mathrm{R}: 5^{\prime}$ - AATTTTGACCCATGATGAAA - $3^{\prime}$ \\
\hline \multirow[t]{2}{*}{ Vitellogenin I } & $\mathrm{F}: 5^{\prime}$ - CACTCATGGCTCTGAGGAA - $3^{\prime}$ \\
\hline & R : 5'- GCAGAGTAAAGACTCAGTTC-3' \\
\hline \multirow[t]{2}{*}{ Vitellogenin II } & F : $5^{\prime}$ - GGGGCATTGATTGCAAGCAGT - $3^{\prime}$ \\
\hline & $\mathrm{R}: 5^{\prime}$ - CTCCTGAAGACCATGGTTAGG - $3^{\prime}$ \\
\hline \multirow[t]{2}{*}{ Estrogenin receptor } & F : $5^{\prime}$ - ACTCCCCTTTACAGCCAGTCC $-3^{\prime}$ \\
\hline & $\mathrm{R}: 5^{\prime}$ - TGGACCAGCTCCTTGTCTGCC - $3^{\prime}$ \\
\hline \multirow[t]{2}{*}{$\beta$-Actin } & F : 5' - TTCAACAGCCCTGCCATGTACG-3' \\
\hline & $\mathrm{R}: 5^{\prime}$ - ATACCGCAGGACTCCATACCAA - $3^{\prime}$ \\
\hline
\end{tabular}

were exposed to $17 \alpha$-ethinylestradiol (Sigma Chemicals, St. Louis, MO, U.S.A.), bisphenol A (Sigma Chemicals) and nonylphenol (Sigma Chemicals), with single concentration of $100 \mu / 1$ for 6 days, respectively. In case of juvenile study, 3 week-old juvenile medaka were exposed to $100 \mu / 117 \alpha$ ethinylestradiol for 6 days. All the chemicals were dissolved in ethyl alcohol, and the control group was exposed to vehicle alone. A semi-static condition was applied for the exposure, and $50 \%$ of the test solution was changed every $24 \mathrm{hr}$.

RNA Extraction and RT-PCR — RNA was carefully extracted from the livers of treated males. Spawning female medaka were used as a control group. In the case of sexually immature juvenile fish, whole body homogenates were used for the RNA purification. For tissue disruption and preparation of total RNA, QIA-Shredder and RNeasy mini-kits (QIAgene, Hilden, Germany) were used according to the manufacture's instructions. Purified RNA samples were diluted at $1 \mu \mathrm{g} / \mu$ l for RT-PCR or stored at $-80^{\circ} \mathrm{C}$ until further use. RT-PCR was performed using $1 \mu \mathrm{g}$ RNA, $1 \mu \mathrm{l}$ of avian myeloblastosis virus (AMV) reverse transcriptase (34 units $/ \mu \mathrm{l}$ ), $1 \mu \mathrm{l}$ of ribonuclease inhibitor( 40 units $/ \mu \mathrm{l}), 4 \mu \mathrm{l}$ of $10 \mathrm{mM}$ deoxyribonucleoside- $5^{\prime}$-triphosphate (dNTPs) and $1 \mu \mathrm{l}$ of oligo deoxythymidine (dT) primers in $20 \mu \mathrm{l}$ total volume at $42^{\circ} \mathrm{C}$ for $30 \mathrm{~min}$ and $99^{\circ} \mathrm{C}$ for $5 \mathrm{~min}$, then $2 \mu \mathrm{l}$ aliquots from the reverse transcription reaction mixture were added to the $48 \mu$ l PCR reaction mixture. Thirty cycles were then performed at $94^{\circ} \mathrm{C}$ for $30 \mathrm{sec}$, at $61^{\circ} \mathrm{C}$ for $30 \mathrm{sec}$, and at $72^{\circ} \mathrm{C}$ for $1 \mathrm{~min}$. RT-PCR was carried out using a program temperature control system (Perkin Elmer 2400). The primers used for the RT-PCR of choriogenin (L: low molecular weight and $\mathrm{H}$ : high molecular weight), ${ }^{9,10)}$ estrogen receptor, ${ }^{11)}$ and $\beta$-actin, ${ }^{12)}$ were synthesized based on the previously known sequence. For the primers of vitellogenin I and II, partial sequencing of the cDNA was done in this study. The sets of primers for RT-PCR are shown in Table 1. The housekeeping gene $\beta$-actin of medaka was used as an internal standard. Aliquots of each amplified cDNA fragment from total $50 \mu \mathrm{l}$ PCR reaction volume were separated on $1.0 \%$ agarose gel.

Partial Sequence of Vitellogenin I and II - $-\mathrm{Re}-$ verse transcription was performed with an RNA template prepared from the livers of spawning females, AMV reverse transcriptase, RNase inhibitor, dNTPs and oligo dT primers in $20 \mu \mathrm{l}$ volume at $42^{\circ} \mathrm{C}$ for $30 \mathrm{~min}$, and then PCR was performed in $50 \mu \mathrm{l}$ total mixture volume for $30 \mathrm{cycles}$ of $94^{\circ} \mathrm{C}$ for $30 \mathrm{sec}$, $58^{\circ} \mathrm{C}$ for $30 \mathrm{sec}$ and $72^{\circ} \mathrm{C}$ for $1 \mathrm{~min}$. For the sequence analysis of vitellogenin (VTG) cDNA, amplification of cDNA specific for the VTG gene from the estrogen-treated medaka was performed using degenerated primers based on the published VTG sequences of other fish species; rainbow trout ${ }^{13)}$ and mummichog. ${ }^{14)}$ Amplified cDNA products were separated on $1.0 \%$ agarose gel by electrophoresis, and the cDNA fragments were cut out from the agarose gel and cloned into pGEM-T easy vector (Promega, Madison, WI, U.S.A.). Then the cDNA clones were applied to the automatic DNA sequencer (ABI3700, Applied Biosystems, Foster City, CA, U.S.A.). Comparison of the cloned cDNA and deduced amino acids with the vitellogenin of other fish species was carried out using the National Center for Biotechnology Information (NCBI) blast search program. 


\begin{abstract}
TCTGCCAATCAATCAGAGTCCTATTGAAGCACTCATGGCTCTGAGGAACATTGCAAAGAAAGAACCAAGA ATGGTTCAGGAACTGGCTCTTCAGCTCTACATGGACAAGGCTCTTGACCCAGAGCTTCGTATGCTTTCAT GCATTGTGCTGTTTGAGACCAATCCTTCAATGGCGCTGATTTCCACCCTTGCCAATGCTGTTAAGTCAGA GGAGAATTGCAGGTTGCCAGCTTCACATACTCTCACATGAAGTCCCTGAGCAGGAGCGCTTCCATGATT CATCCATCAGTAGCTGCAGCTTGTAATGTTGCCATGAAGATCCTGAGTCCAAAGCTGGACAGACTGAGCT TACGTTACAGCAAAGCTGTCTATGGGGAAGCCTATAGCAGCTCTTAAATGCTTGGTGCTGCTGCTACCGC TTTCTACATCAACGATGCTGCTACCTTCCTGCCAAGATCTGTTGTTGCCAAGACCAAAGCCTTCTTTGTT GGAGCTGCTGCTGATGTTCTGGAGATTGGAGTGAGAACTGATGGACTGCAAGAGACCCTTCTGAAAAACO CTTCAATTTCTGACAGTGCTGACAGGATAACAAAAATGAAACGTGTCATCAAGGCTCTTTCTCAGTGGA GATCCTTGCCCAACAACAAACCCTTAGTTTCCTGCTATGTCAAGCTTTTTGGACAAGAGATTGCCTTGCC AACATTGACAAACCCATGATTGAACGGGCTATTGAGCTTGCCAGTGGTCCCTCTGTTCAGGCTTATGGTT TAAAAGCTTTGAAAACTCTGCTCCTTTCTGGTGTCAATTTCCACCATGCAATGCTTGTGCTGTTTAGTGA GGTGCGACGCATATTGCCAACTGCTGCTGGAATCCAGTGGAACTGAGTCTTACTCTGCTGCTGTGGCT GTAGCCGCTGTAGAAATTAAACCAACTCTGTCACCACGTC

(A)
\end{abstract}

AGATCATGACCAGGGTGACATGGGGCATIGATGGAAGCAGIACAACGCTTCATCATCGCTGAAACTGO TCTGGTCGGAAAAGAACCTGCAGCTCGATTGAAAATGACCTGGGAAAGACTCCCTGAGGGCTTGAAAAGA TACGCCAAGTGGGCTTCTGAGTATCTTTCCCGAATTGCTGTTCGCAATGGAGTAAGTCAAGCAAAAGTCA AAAACTTCCAAAAACAGATCCAACTGACAGCTGCTGTCAATGAGACAAACCTAAATGTTACACTGAAGAC ACCTCAGAGTACTCTATACAAACTTGGATTGGGTCTTCCAATTTCTTTACCCCTTGGAGAAACTGCTGCT GAGTTGGAGGCCTATCCTGAAAGCTGGCCTGGCAAACTGTCCTACATGCTCACCAAAGCCCATGCTGCTC AGTGCATCTTGGTCAATGACAGCCTGATCACGTTCAACAACAAAAAATACAAAAATGAGATGCCCCATTC TTGCTACCAGGTCTTGGCTCAAGATTGCACATCAGAACTCAAATTCATGGTTCTGCTGAAGCGAGACCAA ACTGCAGAACAGAACGAGATTAATGTCAAGATTGAAAACATGGACATTGACATTTATTTAAGGGACAATO CTACTGTGGTGAAAGTCAACAGCGTGGAAATCCTTTCTGCCAACATGCCCTATCAGCATTCAACAGGCAA TATACAGATCAGAGAGAAGGCTGAGGGTGTTTCTCTGCATGCACCTAACCATGGTCTHCAGGAGGTCTTC ITCAACCATACTACAGTGAAGGTTCAATTGCCGACTGGATGAGAGGAAAGACTTGTGGACTATGTGGAA AGGCCGACGGTGAAGTCAAGGAAGAGTATCGCACACCCAACGAGCGAGTGTCTAAGAATGCAACCACCTT TGCTCATTCCTGGGTTCTGTCGGGACAGAGCTGCCGCCATACCTCTGAGTGCTACATGAAACTTGAGTCT GTGAAGCTGGAGAAGCAGGTCAACCACTTAGGGGAAGATTCTAAATGCTACTTCTGTTGAGCCTGTGCT CGCTGTCTTCCCGGCTGTATGCCTACAAGAAAAACCACTGTCAATGTCGGATACCATTGTCTACCCATTO GTACAAATTTAAATCGTAATGACGGCCTCAACAGCATCTTTGAGAAGAGCATTGATTTGAGGGAGACCGC AGAGGCTCATCTTGCTTGTCGCTGCACAGCTCAGTGTGCATAATTTTATAACTTTGATCATGTTATACTO TGTITITAACCAAGGTTGTAAACTTAAATAAAATATAAAGGCATGTTAAAAAAAAAAAA

(B)

Fig. 1. Partial cDNA Sequences of Medaka Vitellogenin I (A) and Vitellogenin II (B)

Underlined parts of the nucleotide sequences were used for the primers of RT-PCR for vitellogenin I and II, respectively.

\section{RESULTS AND DISCUSSION}

VTG, choriogenin (Chg), and estrogen receptor (ER) were compared in male medaka exposed to estrogenic chemicals $17 \alpha$-ethinylestradiol (EE2), bisphenol A, and nonylphenol. A comparison study was also done in sexually immature juvenile medaka. The synthetic oligo-primer sequences used for RTPCR of medaka Chg and ER were designed according to previously reported cDNA sequences. ${ }^{9-11)}$ To design suitable oligo-primers for VTG RT-PCR, partial cDNA fragments were isolated from the estrogen-treated medaka, then two cDNA clones were acquired (Fig. 1). As a result of sequence comparison with VTG genes of other fish species, these two cDNA clones showed high homology with VTG of various fish species; therefore, they were confirmed as the parts of medaka VTG I and VTG II, respectively. $950 \mathrm{bp}$ partial cDNA fragment of medaka VTG I showed a high degree of amino acid sequence similarity to mummichog VTG I (71\%), rainbow trout VTG (61\%), common carp VTG (53\%), and zebrafish VTG (53\%). A 1320 bp partial fragment

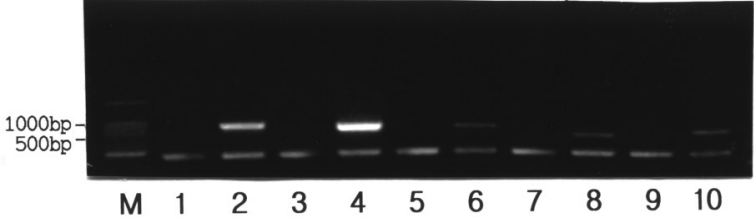

Fig. 2. Induction of mRNA of Choriogenin, Vitellogenin and Estrogen Receptor by $17 \alpha$-ethinylestradiol

Male medaka were treated with $100 \mathrm{ug} / 1$ of $17 \alpha$-ethinylestradiol. RT-PCR was performed for 30 cycles. Upper bands are amplified cDNA fragments of biomarker genes, and lower bands are cDNA fragments of $\beta$-actin(440 bp) as an internal control. M: size markers, choriogenin $\mathrm{H}$ (1: control, 2: treated), choriogenin L (3: control, 4: treated), VTG I (5: control, 6: treated), VTG II (7: control, 8: treated), estrogen receptor (9: control, 10: treated).

of medaka VTG II had an amino acid sequence similar to mummichog VTG II (63\%) and rainbow trout VTG (50\%). Based on these cDNA sequence data of VTG, suitable oligo-primers of VTG I and VTG II RT-PCR were synthesized, respectively. All the primers of the biomarker genes used in this study are shown in Table 1.

Treatment of mature males with EE2 resulted in pronounced elevation of Chg and VTG mRNA levels. However, the ER mRNA level was relatively weak in comparison with Chg and VTG. The estimated size of the amplified RT-PCR products of the biomarker genes are as follows: $900 \mathrm{bp}$ of choriogenin $\mathrm{H}, 860$ bp of choriogenin L, $870 \mathrm{bp}$ of vitellogenin I, $740 \mathrm{bp}$ of vitellogenin II and $850 \mathrm{bp}$ of estrogen receptor, respectively. Amplified cDNA fragments of these genes were not detected in the non-treated group, and $\beta$-actin cDNA fragments used as an internal standard were approximately equally expressed in the treated and control groups (Fig. 2). When we compared the sensitivity of VTG, Chg, and ER genes at the same concentration of EE2 by performing RT-PCR for 30 cycles, respectively, Chg $\mathrm{L}$ was shown to be the most responsive to EE2 in all the biomarkers tested in adult male medaka, and also in juvenile medaka (Fig. 3A and 3B). Choriogenin $\mathrm{H}$ and $\mathrm{L}$ were shown to be more sensitive than those of vitellogenin, and this result supported previous reports. ${ }^{15)}$ This pattern of responsiveness was also shown in the nonylphenol- or bisphenol A- treated male medaka, although the estrogen receptor did not seem to be induced in the concentration of $100 \mu \mathrm{g} / \mathrm{l}$ of the chemicals (Fig. 4A and 4B). mRNA of the estrogen receptor could be induced in a higher concentration of nonylphenol or bisphenol A than that used in this test. The sensitivity between vitellogenin I and II could not be assured because this study did 
A

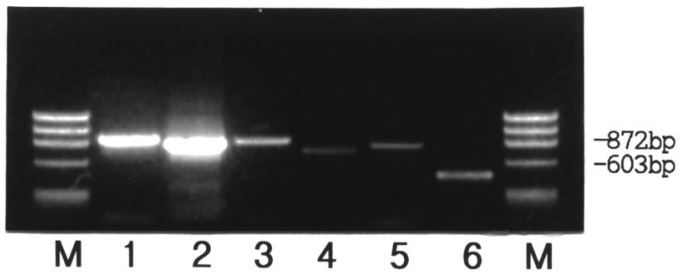

B

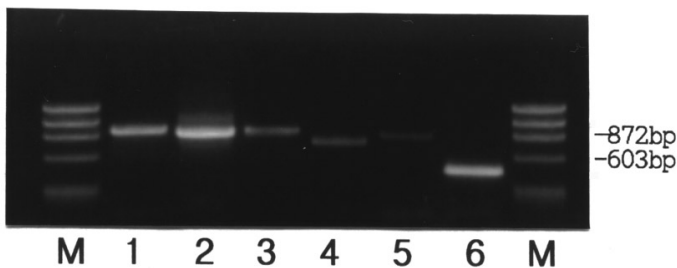

Fig. 3. RT-PCR of Choriogenin, Vitellogenin and Estrogen Receptor in Adult Male Medaka (A) and Juvenile Medaka (B) Exposed to $100 \mu \mathrm{g} / \mathrm{l}$ of $17 \alpha$-ethinylestradiol RT-PCR was performed for 30 cycles (M: size marker $\phi \times 173-$ HaeIII, 1: choriogenin H, 2: choriogenin L, 3: vitellogenin I, 4: vitellogenin II, 5: estrogen receptor, 6: $\beta$-actin).

A

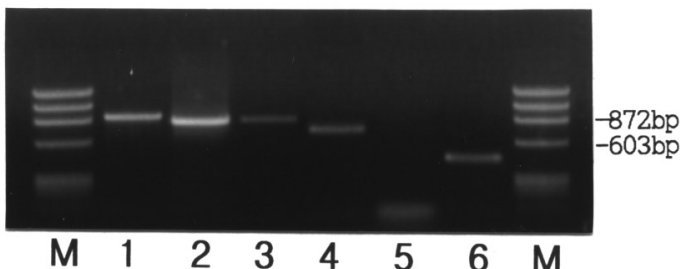

B

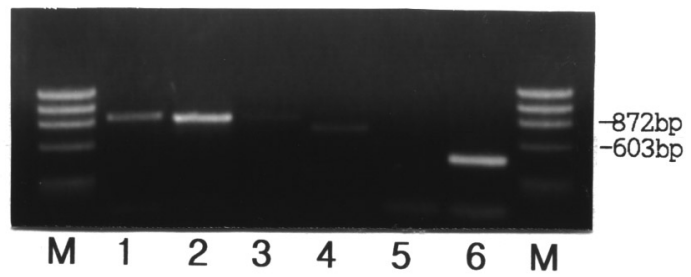

Fig. 4. RT-PCR of Choriogenin, Vitellogenin and Estrogen Receptor in Mature Male Medaka Exposed to $100 \mu \mathrm{g} / \mathrm{l}$ of Nonylphenol (A) and Bisphenol A (B), Respectively RT-PCR was performed for 30 cycles (M: size marker $\phi \times 173-$ HaeIII, lane 1: choriogenin H, 2: choriogenin L, 3: vitellogenin I, 4: vitellogenin II, 5: estrogen receptor, 6: $\beta$-actin ).

not cover various concentrations. The sensitivity patterns of the five biomarkers tested in this study were almost the same in sexually immature juvenile medaka as in sexually mature male fish.

\section{REFERENCES}

1) Sumpter, J. P. (1998) Xenoendocrine disruptersenvironmental impacts. Toxicol. Lett., 103, 337-342.

2) Endocrine Disruptors Testing and Assessment Task Force (2000) Report from the $2^{\text {nd }} O E C D$ Expert
Consultation on Endocrine Disrupters Testing in Fish (EDF2), Tokyo, $15^{\text {th }}-16^{\text {th }}$, March, 2000, OECD, Tokyo, Japan.

3) Lattier, D. L., Gordon, D. A., Burks, D. J. and Toth, G. P. (2001) Vitellogenin gene transcription: relative quantitative exposure indicator of environmental estrogens. Environ. Toxicol. Chem., 20, 1979-1985.

4) Cheek, A. O., Brouwer, T. H., Carroll, S., Manning, S., McLachlan, J. A. and Brouwer, M. (2001) Experimental evaluation of vitellogenin as a predictive biomarker for reproductive disruption. Environ. Health. Perspect., 109, 681-690.

5) Celius, T., Matthews, J. B., Giesy J. P. and Zacharewski, T. R. (2000) Quantification of rainbow trout (Oncorhynchus mykiss) zona radiata and vitellogenin mRNA levels using real-time PCR after in vivo treatment with estradiol-17 beta or alphazearalenol. J. Steroid Biochem. Mol. Biol., 75, 109119.

6) Asai, D., Tahara, Y., Nakai, M., Yakabe, Y., Takatsuki, M., Nose, T., Shinmyozu, T. and Shimohiogashi, Y. (2000) Structural essentials of xenoestrogen dialkyl phthalates to bind to the estrogen receptors. Toxicol. Lett., 118, 1-8.

7) Scholz, I. R., Orner, G., Merdink, J. L. and Skillman, A. (2000) 17 $\alpha$-ethinylestradiol affects reproduction, sexual differentiation and aromatase gene expression of the medaka (Oryzias latipes). Aquat. Toxicol., 50, 363-373.

8) Celius, T. and Walther, B. T. (1998) Differential sensitivity of zonagenesis and vitellogenesis in Atlantic salmon (Salmo salar L) to DDT pesticides. J. Exp. Zool., 281, 346-553.

9) Murata, K., Sasaki, T., Yasumasu, S., Iuchi, I., Enami, J., Yasumasu, I. and Yamagami, K. (1995) Cloning of cDNAs for the precursor protein of a lowmolecular-weight subunit of the inner layer of the egg envelope (chorion) of the fish Oryzias latipes. Dev. Biol., 167, 9-17.

10) Murata, K., Sugiyama, H., Yasumasu, S., Iuchi, I., Yasumasu, I. and Yamagami, K. (1997) Cloning of cDNA and estrogen-induced hepatic gene expression for choriogenin $\mathrm{H}$, a precursor protein of the fish egg envelope (chorion). Proc. Natl. Acad. Sci. U.S.A., 94, 2050-2055.

11) Okada, H., Kawahara, T. and Yamashita, I. (1994) Oryzias sp. mRNA for estrogen receptor, complete cds. NCBI D28954. www.ncbi.nlm.nih.gov.

12) Takagi, S., Sasado, T., Tamiya, G., Ozato, K., Wakamatsu, Y., Takeshita, A. and Kimura, M. (1994) An efficient expression vector for transgenic medaka construction. Mol. Mar. Biol. Biotechnol., 3, 192199.

13) Nathalie, M., Valerie, T., Alexis, B., Jean-Paul, L. P. and Jacques, W. (1996) Characterization of 
vitellogenin from rainbow trout (Oncorhynchus mykiss). Gene, 174, 59-64.

14) LaFleur, G. J., Byrne, B. M., Kanungo, J., Nelson, L. D., Greenberg, R. M. and Wallace, R. A. (1995) Fundulus heteroclitus vitellogenin: the deduced primary structure of a piscine precursor to noncrystalline, liquid-phase yolk protein. J. Mol.
Evol., 41, 505-521.

15) Arukwe, A., Celius, T., Walther, B. and Goksoyr, A. (2000) Effects of xenoestrogen treatment on zona radiata protein and vitellogenin expression in Atlantic salmon (Salmo salar). Aquatic Toxicol., 49,159-170. 